\title{
Hemoglobin target in chronic kidney disease: a pediatric perspective
}

\author{
Sai Ram Keithi-Reddy • Ajay K. Singh
}

Received: 20 December 2007 /Revised: 4 May 2008 / Accepted: 5 May 2008 / Published online: 5 July 2008

(C) IPNA 2008

\begin{abstract}
Erythropoietin has transformed the treatment of the anemia of chronic kidney disease (CKD) by preventing the need for blood transfusions and improving the quality of life in all patients, including children. Anemia in children, in the age group 1-19 years, may be defined as hemoglobin (Hgb) levels $<12.1-13.5 \mathrm{~g} / \mathrm{dl}$ for boys and $<$ 11.4-11.5 g/dl for girls, based on the National Health and Nutrition Examination Survey (NHANES) norms. The prevalence of anemia in children ranges from $31.2 \%$ in stage $1 \mathrm{CKD}$ to $93.3 \%$ in stages 4 and $5 \mathrm{CKD}$. The recent publication of trials evaluating the optimal hemoglobin level in adult CKD patients has generated considerable uncertainty about the target Hgb level in children with CKD. It is unclear whether generalizing of results from these trials in adults to children is appropriate. Adequately powered, randomized, controlled studies have not been conducted on children, and none to our knowledge are currently planned. The Food and Drug Administration (FDA) offers scant guidance on the Hgb target level for children, other than implying that it should be no different from that for adults. The purpose of this editorial is to critically scrutinize whether there is a benefit to the normalization of anemia in children with CKD and whether adoption of the results from adult studies is appropriate.
\end{abstract}

S. R. Keithi-Reddy $\cdot$ A. K. Singh

Renal Division, Brigham and Women's Hospital

and Harvard Medical School,

Boston, MA, USA

\section{A. K. Singh $(\triangle)$}

Dialysis Services, Brigham and Women's Hospital,

75 Francis Street,

Boston, MA 02115, USA

e-mail: asingh@partners.org
Keywords Erythropoietin - Anemia $\cdot$ CKD $\cdot$ Pediatric . Hemoglobin

The benefits and risks of normalizing the hemoglobin level for children with chronic kidney disease

Proponents of the normalization of hemoglobin levels in chronic kidney disease (CKD) have argued for the diverse benefits of correcting anemia in children. These benefits include improvements in quality of life, cognitive function, exercise capacity, scholastic performance, growth and nutrition, and cardiovascular function [1]. Quality of life (QOL) and its components have frequently been used as surrogate outcome measures for children, since they influence physical performance, exercise tolerance, and even school attendance. However, studies demonstrating these benefits have largely been small in sample size, nonrandomized in design, of short duration, and have used nonvalidated instruments [2-5]. In a multi-center interventional trial that evaluated intelligence quotient (IQ) using the Weschler intelligence test, treatment of anemia was associated with a significant increase in IQ [6]. However, the design was limited by a single-arm and a sample size of only 22 children with CKD. With respect to growth, many trials have demonstrated a lack of effect of anemia correction on growth in children with CKD [1]. Recent studies have not only demonstrated a high prevalence of growth retardation in children with chronic kidney disease but have also suggested that initial hemoglobin (Hgb) level and early treatment with erythropoietin is associated with improved growth [7]. While these studies have limitations, including retrospective design and small numbers (47 children), they have been influential in supporting normalization of Hgb level in children with CKD. The evidence 
for improvement in cardiovascular co-morbidity in children with treatment of anemia rests on the results of a single, randomized, placebo-controlled trial comprised of only 11 children undergoing dialysis. In that study, patients were assigned to therapy with erythropoiesis-stimulating agents (ESAs) or to placebo for 24 weeks. ESA therapy was associated with partial correction of an elevated cardiac index at 6 months and a significant reduction in left ventricular mass at 12 months [8]. The subjects in that study were severely anemic, with baseline $\mathrm{Hgb}$ of $7.3 \mathrm{~g} / \mathrm{dl}$. It was suggested that these data were concordant with those from two observational studies providing further resonance to the importance of anemia treatment [9]. A recent study examined 677 adolescents on hemodialysis for the relationship between $\mathrm{Hgb}$ level and the risk for death or hospitalization [10]. Patients with $\mathrm{Hgb} \geq 11 \mathrm{~g} / \mathrm{dl}$ consistently demonstrated a $60 \%$ to $70 \%$ decrease in the risk of death. However, mortality was similar for patients with Hgb levels of $11 \mathrm{~g} / \mathrm{dl}$ to $12 \mathrm{~g} / \mathrm{dl}$ and $>12 \mathrm{~g} / \mathrm{dl}$ when compared with those with $\mathrm{Hgb}<10 \mathrm{~g} / \mathrm{dl}$, and no significant difference in risk for hospitalization was observed between the various $\mathrm{Hgb}$ categories. Warady and Ho, using data from the North American Pediatric Renal Transplant Cooperative Study (NAPRTCS), reported an association between a baseline hematocrit less than $33 \%$ at 30 days after initiation of dialysis and increased risk for prolonged hospitalization and death in patients with incident end-stage renal disease (ESRD) who were younger than 18 years of age [11]. A study by Furth et al. suggested an association of greater decline in glomerular filtration rate (GFR) with hematocrit less than $36 \%$, reiterating the importance of correction of anemia [12].

Balanced against the potential benefits of epoetin in correcting CKD are the risks of hypertension, thrombosis and atherosclerosis [13]. Exacerbation of hypertension has been reported by several authors in both non-dialysis CKD and children on dialysis [14-19]. However, many of the studies excluded children with moderate or uncontrolled hypertension, either before or during the trial period. Vaziri and co-workers, in both humans and animal models, have explored the mechanism of hypertension. Vaziri has suggested that erythropoietin-induced hypertension is a nitric oxide-mediated complication [20]. Consequently, the use of lower doses of epoetin (approximately $150 \mathrm{U} / \mathrm{kg}$ per week) is recommended. In light of studies supporting a prothrombotic potential of epoetin in children, it has been suggested that epoetin administration be deferred for at least 2 weeks after surgery for arteriovenous (AV) fistula to prevent fistula thrombosis $[13,14,21]$.

The mechanism by which epoetin might increase cardiovascular risk remains unclear, even though studies in the adult CKD and dialysis population demonstrate either no benefit or increased cardiac events and mortality when higher doses of epoetin are used to achieve a higher $\mathrm{Hgb}$ concentration [22-24]. The reason for the higher incidence of adverse events remains obscure; however, the presence of erythropoietin receptors in organs other than the bone marrow, such as the vascular endothelium, the myocardium, the kidneys, and the central nervous system, raises the possibility that there may be non-erythropoetic effects of erythropoietin that might explain the adverse risk $[20,25]$.

Since there have been no large randomized controlled trials in children, the correction of the risk of anemia in children is largely based on extrapolation from adult randomized controlled trials (RCTs). Two RCTs have been cited by the Food and Drug Administration (FDA) in their black box warning: one in hemodialysis patients - the Normal Hematocrit study (NHS), and the other in nondialysis patients - the Correction of Hgb and Outcomes in Renal Insufficiency (CHOIR) study. The NHS trial randomly assigned 1,223 symptomatic hemodialysis patients to a hematocrit of $42 \%$ versus $30 \%$ with high-dose and lower-dose epoetin treatment, respectively [24]. Patients were considered to be at high risk of cardiovascular disease, because they were required to have congestive heart failure or ischemic heart disease on enrollment. The primary endpoint was the length of time to death or a first nonfatal myocardial infarction. The study was terminated early by the data monitoring committee, at the third interim analysis, because of the higher risk observed in patients randomly assigned to the higher hematocrit arm of the trial. The study demonstrated increased risk for patients assigned to the higher hematocrit [relative risk (RR) of 1.3]. The study also reported a higher rate of vascular thrombosis in patients treated to the higher hematocrit. However, the study did not address the benefit or harm of maintaining hematocrit between $30 \%$ and $42 \%$. The CHOIR study was an open-label, randomized trial that studied 1,432 patients with non-dialysis CKD across 131 centers in the USA; 715 patients were randomly assigned to receive epoetin alpha targeted to achieve an Hgb level of $13.5 \mathrm{~g} / \mathrm{dl}$, and 717 were randomly selected to receive epoetin alpha targeted to achieve an Hgb level of $11.3 \mathrm{~g} / \mathrm{dl}$ [22]. Eligibility criteria included age $>18$ years and an estimated GFR of 15$50 \mathrm{ml} / \mathrm{min}$ per $1.73 \mathrm{~m}^{2}$ body surface area. The primary endpoint was a composite of death, myocardial infarction, congestive heart failure (CHF) hospitalization (excluding hospitalization during which renal replacement therapy occurred) and stroke. Secondary endpoints included the components of the primary endpoint, as well as cardiovascular and total hospitalizations, QOL and the time-todialysis. There were 222 composite events: 125 in the high Hgb group and 97 in the low Hgb group $[P=0.03$, hazard ratio (HR) 1.34; with $95 \%$ confidence interval of 1.03 and 1.74]. The higher rate of composite events was explained largely by a higher rate of death ( $48 \%$ higher risk, $P=0.07)$ 
or CHF hospitalization $(41 \%, P=0.07)$. The QOL improved in both groups but did not differ significantly. These trials were supported by a recent meta-analysis that concluded that, when an Hgb level $>12 \mathrm{~g} / \mathrm{d}$ is aimed for, there is a $17 \%$ higher risk of mortality. The higher mortality was attributed to higher risk of cardiovascular complications [26]. Despite these studies in adults, higher doses of epoetin are being used in children to achieve normalization of hematocrit based on data from the NAPRTCS 2001 and 2004 registry reports [27]. In this report, younger children are being given higher doses of erythropoietin (EPO), with infants requiring the highest dose, ranging from $275 \mathrm{U} / \mathrm{kg}$ per week to $350 \mathrm{U} / \mathrm{kg}$ per week [28].

\section{Recommendations for the optimal Hgb level in children}

Based on RCTs in adults and largely observational studies in children, an opinion-based minimum Hgb level of $11 \mathrm{~g} /$ dl has been recommended by the European Pediatric Peritoneal Dialysis Working Group (EPPWG) and National Kidney Foundation Kidney Disease Outcome Quality Initiative (NKF-K/DOQI) with the rationale of improved quality of life and better survival [2, 29, 30]. In addition, the EPPWG has recommended the use of iron as an adjunct to epoetin in the treatment of anemia. Studies of adults have also suggested that, among adult patients suffering inflammation and on permanent hemodialysis, when an increase in the dose of epoetin is contemplated, administration of $1 \mathrm{~g}$ of ferric gluconate is effective in improving hemoglobin levels $[31,32]$. The EPPWG did not recommend an upper limit for the Hgb level, while NKF-K/DOQI has most recently suggested that $\mathrm{Hgb}$ levels should be 11 to $12 \mathrm{~g} / \mathrm{dl}$ $[29,30]$. The FDA has most recently stated that the optimal $\mathrm{Hgb}$ level in adults (and children) with CKD should be in the $10 \mathrm{~g} / \mathrm{dl}$ to $12 \mathrm{~g} / \mathrm{dl}$ range. The optimal target level of $\mathrm{Hgb}$ in children is compounded by the age-related variation in defining the normal $\mathrm{Hgb}$ concentration and, consequently, the anemic range [33]. Additionally, the variability in $\mathrm{Hgb}$ concentration - a phenomenon called Hgb cycling-results in quite considerable difficulty in maintaining $\mathrm{Hgb}$ targets between $11 \mathrm{~g} / \mathrm{dl}$ and $12 \mathrm{~g} / \mathrm{dl}$. Hgb cycling is defined as a non-physiological oscillation or periodic fluctuation in the $\mathrm{Hgb}$ level by more than $1.5 \mathrm{~g} / \mathrm{dl}$ from an equilibrium point. Over $90 \%$ of adult hemodialysis patients demonstrate at least one $\mathrm{Hgb}$ cycle in a year [34]. To our knowledge, hemoglobin cycling has not been studied in children.

In conclusion, there are limited data that address the hemoglobin target levels in children with CKD. Since children have important physiologic differences from adults, and since the effects of the complications of CKD, including anemia, may be different in children than in adults, RCTs in children are desperately needed. However, until randomized controlled studies of children with $\mathrm{CKD}$ are conducted, adult studies should help guide the decision in children. At this point we recommend aiming for an $\mathrm{Hgb}$ level of $10 \mathrm{~g} / \mathrm{dl}$ to $12 \mathrm{~g} / \mathrm{dl}$ in children, commensurate with the FDA guidelines.

\section{References}

1. Jabs K (1996) The effects of recombinant human erythropoietin on growth and nutritional status. Pediatr Nephrol 10:324-327

2. Gerson A, Hwang W, Fiorenza J, Barth K, Kaskel F, Weiss L, Zelikovsky N, Fivush B, Furth S (2004) Anemia and healthrelated quality of life in adolescents with chronic kidney disease. Am J Kidney Dis 44:1017-1023

3. Kurtin PS, Landgraf JM, Abetz L (1994) Patient-based health status measurements in pediatric dialysis: expanding the assessment of outcome. Am J Kidney Dis 24:376-382

4. Morris KP, Sharp J, Watson S, Coulthard MG (1993) Non-cardiac benefits of human recombinant erythropoietin in end stage renal failure and anaemia. Arch Dis Child 69:580-586

5. Van Damme-Lombaerts R, Broyer M, Businger J, Baldauf C, Stocker H (1994) A study of recombinant human erythropoietin in the treatment of anaemia of chronic renal failure in children on haemodialysis. Pediatr Nephrol 8:338-342

6. Halterman JS, Kaczorowski JM, Aligne CA, Auinger P, Szilagyi PG (2001) Iron deficiency and cognitive achievement among school-aged children and adolescents in the United States. Pediatrics 107:1381-1386

7. Boehm M, Riesenhuber A, Winkelmayer WC, Arbeiter K, Mueller T, Aufricht C (2007) Early erythropoietin therapy is associated with improved growth in children with chronic kidney disease. Pediatr Nephrol 22:1189-1193

8. Morris KP, Skinner JR, Hunter S, Coulthard MG (1994) Cardiovascular abnormalities in end stage renal failure: the effect of anaemia or uraemia? Arch Dis Child 71:119-122

9. Mitsnefes MM, Kimball TR, Border WL, Witt SA, Glascock BJ, Khoury PR, Daniels SR (2004) Impaired left ventricular diastolic function in children with chronic renal failure. Kidney Int 65:1461-1466

10. Amaral S, Hwang W, Fivush B, Neu A, Frankenfield D, Furth S (2006) Association of mortality and hospitalization with achievement of adult hemoglobin targets in adolescents maintained on hemodialysis. J Am Soc Nephrol 17:2878-2885

11. Warady BA, Ho M (2003) Morbidity and mortality in children with anemia at initiation of dialysis. Pediatr Nephrol 18:1055-1062

12. Furth SL, Cole SR, Fadrowski JJ, Gerson A, Pierce CB, Chandra M, Weiss R, Kaskel F (2007) The association of anemia and hypoalbuminemia with accelerated decline in GFR among adolescents with chronic kidney disease. Pediatr Nephrol $22: 265-271$

13. Van Geet C, Van Damme-Lombaerts R, Vanrusselt M, de Mol A, Proesmans W, Vermylen J (1990) Recombinant human erythropoietin increases blood pressure, platelet aggregability and platelet free calcium mobilisation in uraemic children: a possible link? Thromb Haemost 64:7-10

14. Bianchetti MG, Hammerli I, Roduit C, Neuhaus TJ, Leumann EP, Oetliker OH (1991) Epoetin alfa in anaemic children or adolescents on regular dialysis. Eur J Pediatr 150:509-512

15. Offner G, Hoyer PF, Latta K, Winkler L, Brodehl J, Scigalla P (1990) One year's experience with recombinant erythropoietin in children undergoing continuous ambulatory or cycling peritoneal dialysis. Pediatr Nephrol 4:498-500 
16. Sinai-Trieman L, Salusky IB, Fine RN (1989) Use of subcutaneous recombinant human erythropoietin in children undergoing continuous cycling peritoneal dialysis. J Pediatr 114:550-554

17. Brandt JR, Avner ED, Hickman RO, Watkins SL (1999) Safety and efficacy of erythropoietin in children with chronic renal failure. Pediatr Nephrol 13:143-147

18. Warady BA, Arar MY, Lerner G, Nakanishi AM, Stehman-Breen C (2006) Darbepoetin alfa for the treatment of anemia in pediatric patients with chronic kidney disease. Pediatr Nephrol 21:1144-1152

19. Scharer K, Klare B, Braun A, Dressel P, Gretz N (1993) Treatment of renal anemia by subcutaneous erythropoietin in children with preterminal chronic renal failure. Acta Paediatr 82:953-958

20. Vaziri ND (2001) Cardiovascular effects of erythropoietin and anemia correction. Curr Opin Nephrol Hypertens 10:633-637

21. Van Damme-Lombaerts R, Herman J (1999) Erythropoietin treatment in children with renal failure. Pediatr Nephrol 13:148-152

22. Singh AK, Szczech L, Tang KL, Barnhart H, Sapp S, Wolfson M, Reddan D (2006) Correction of anemia with epoetin alfa in chronic kidney disease. N Engl J Med 355:2085-2098

23. Drueke TB, Locatelli F, Clyne N, Eckardt KU, Macdougall IC, Tsakiris D, Burger HU, Scherhag A (2006) Normalization of hemoglobin level in patients with chronic kidney disease and anemia. N Engl J Med 355:2071-2084

24. Besarab A, Bolton WK, Browne JK, Egrie JC, Nissenson AR, Okamoto DM, Schwab SJ, Goodkin DA (1998) The effects of normal as compared with low hematocrit values in patients with cardiac disease who are receiving hemodialysis and epoetin. $\mathrm{N}$ Engl J Med 339:584-590

25. Fishbane S, Nissenson AR (2007) The new FDA label for erythropoietin treatment: how does it affect hemoglobin target? Kidney Int 72:806-813
26. Phrommintikul A, Haas SJ, Elsik M, Krum H (2007) Mortality and target haemoglobin concentrations in anaemic patients with chronic kidney disease treated with erythropoietin: a metaanalysis. Lancet 369:381-388

27. Seikaly MG, Ho PL, Emmett L, Fine RN, Tejani A (2003) Chronic renal insufficiency in children: the 2001 Annual Report of the NAPRTCS. Pediatr Nephrol 18:796-804

28. Port RE, Kiepe D, Van Guilder M, Jelliffe RW, Mehls O (2004) Recombinant human erythropoietin for the treatment of renal anaemia in children: no justification for bodyweight-adjusted dosage. Clin Pharmacokinet 43:57-70

29. Schroder CH (2003) The management of anemia in pediatric peritoneal dialysis patients. Guidelines by an ad hoc European committee. Pediatr Nephrol 18:805-809

30. KDOQI, National Kidney Foundation (2006) II. Clinical practice guidelines and clinical practice recommendations for anemia in chronic kidney disease in adults. Am J Kidney Dis 47(5 Suppl 3): S16-S85

31. Coyne DW, Kapoian T, Suki W, Singh AK, Moran JE, Dahl NV, Rizkala AR (2007) Ferric gluconate is highly efficacious in anemic hemodialysis patients with high serum ferritin and low transferrin saturation: results of the Dialysis Patients' Response to IV Iron with Elevated Ferritin (DRIVE) Study. J Am Soc Nephrol 18:975-984

32. Kapoian T, O'Mara NB, Singh AK, Moran J, Rizkala AR, Geronemus R, Kopelman RC, Dahl NV, Coyne DW (2008) Ferric gluconate reduces epoetin requirements in hemodialysis patients with elevated ferritin. J Am Soc Nephrol 19:372-379

33. Filler G, Mylrea K, Feber J, Wong H (2007) How to define anemia in children with chronic kidney disease? Pediatr Nephrol 22:702-707

34. Fishbane S, Berns JS (2005) Hemoglobin cycling in hemodialysis patients treated with recombinant human erythropoietin. Kidney Int 68:1337-1343 